\title{
Afectación al principio de selección objetiva a través de la celebración de convenios o contratos interadministrativos
}

Andrés Mauricio Quiceno Arenas ${ }^{1}$

\section{RESUMEN}

Los convenios y contratos interadministrativos son una de las causales para la selección directa del contratista en el régimen de contratación pública en Colombia. Se trata de verdaderos contratos de colaboración, en los que existe unión de esfuerzos entre entidad contratante y contratista, para la consecución de finalidades públicas. Por el uso indebido de la institución, así como la elusión de procedimientos de selección, la misma resulta cuestionada, al punto de pensarse en su eliminación del ordenamiento contractual colombiano. El presente trabajo aborda la conceptualización y los rasgos diferenciadores de ambas instituciones, así como la problemática específica presentada, y propone algunas soluciones comunicativas y legislativas que redunde en el beneficio de la tipología contractual.

1 Magíster en Derecho con énfasis en Derecho Administrativo de la Universidad Externado de Colombia, Bogotá, Colombia. Abogado consultor en contratación estatal y responsabilidad de los servidores públicos. Asesor jurídico externo de la Universidad del Quindío y de las Empresas Públicas del Quindío en materia de contratación estatal, Armenia, Colombia. Correo-e: andres.quiceno@aqconsultorias.com. Enlace ORCID: https://orcid.org/00000003-4057-6242. Fecha de recepción: 2 de marzo de 2020. Fecha de modificación: 30 de marzo de 2020. Fecha de aceptación: 2 de mayo de 2020. Para citar el artículo: QuicenO AREnAS, ANDrÉS MAURICIO, "Afectación del principio de selección objetiva a través de la celebración de convenios o contratos interadministrativos", Revista digital de Derecho Administrativo, Universidad Externado de Colombia, n. ${ }^{\circ} 24,2020$, pp. 103-126. DOI: https://doi. org/10.18601/21452946.n24.05. 
Palabras clave: contrato administrativo, cooperación administrativa, licitación pública, arbitrariedad, abuso de poder, procedimientos de selección competitivos.

\title{
Breach of the Objective Selection Principle Through the Celebration of Inter-Administrative Agreements or Contracts
}

\begin{abstract}
Inter-administrative agreements and contracts are some of the exceptions to competitive bidding or selection procedures in public procurement in Colombia. These are true collaboration contracts, justified by the union of efforts of the contracting entity and the contractor, for the achievement of public purposes. Because of an improper use of these contracts and agreements, as well as the avoidance of competitive selection procedures, these types of procurements are questioned. The present work addresses the concept and distinctive features of these institutions, the specific problem of dodging competitive bids, and suggests some communicative and legislative solutions that result in the benefit of the contractual typology.
\end{abstract}

Keywords: Public Procurement, Administrative Cooperation, Public Tender, Arbitrariness, Abuse of Power, Competitive Bidding Procedures.

\section{INTRODUCCIÓN}

Algunos de los problemas jurídicos que sufren los funcionarios y servidores públicos ocurren como consecuencia de la indebida aplicación o interpretación de las normas de contratación estatal. Es una problemática constante que se inicien investigaciones disciplinarias o que se imputen cargos por conductas relacionadas con la celebración indebida de contratos. Es más, se ha recurrido a la estrategia de lucha contra la corrupción en estos casos, aludiendo a que la celebración de contratos es, usualmente, el mecanismo que se utiliza para la obtención indebida de recursos del erario y para su apropiación por ordenadores de gasto y particulares.

Lo pretérito es producto de un ordenamiento jurídico contractual formalista, que pretende, a través de ritualidades y procedimientos rigurosamente regulados, garantizar los principios de la función pública, de la gestión fiscal, de la actuación administrativa y de la contratación estatal2. Se presume por el legislador y el ejecutivo, a través de los reglamentos, que la expedición de 
procedimientos altamente complicados se verá traducida en prácticas transparentes, imparciales y objetivas al momento de la celebración de contratos con el Estado.

No obstante, dicha creencia es falsa. Ello se debe, en primer lugar, a que la imposición de procedimientos engorrosos aleja a la ciudadanía de la participación en los procedimientos selectivos. Además, porque esas mismas formalidades han sido utilizadas como argucias para facilitar prácticas corruptas, en la que particulares y servidores públicos cohonestan con prácticas colusorias para la apropiación de recursos públicos, que tienen como fuente la intencionalidad de lucrarse irregularmente, o el pago de los dineros que fueron destinados a la financiación de las campañas políticas. Por último, debido a la multiplicidad de procedimientos selectivos, filosóficamente concebidos, en los cuales, la licitación pública, como el procedimiento ideal, termina siendo la excepcionalidad, en tanto su criterio es la residualidad.

Estando clara dicha situación, también es posible afirmar que el uso desbordado de la contratación directa como mecanismo de selección objetiva de contratistas es una de las prácticas más cotidianas y que deja un halo de corrupción tras su celebración. Se presupone por la sociedad que la celebración de contratos a través de contratación directa es traducción inmediata de corrupción, lo que también es equivocado.

Ahora bien, en este panorama se encuentra que una de las tipologías que se señalan como medio para la consolidación de prácticas corruptas es el convenio o contrato interadministrativo. Los órganos de control, los medios de comunicación y, en general, el operador jurídico entiende estos tipos contractuales como foco tradicional de corrupción. Sin embargo, esta afirmación, sin condicionamiento alguno, carece de sustento.

Lo que no se puede negar es, precisamente, que algunos administradores han recurrido a la contratación directa, a través de la celebración de contratos y convenios interadministrativos (e incluso de convenios interinstitucionales), para legalizar el quebrantamiento de los principios que rigen la contratación estatal, y de dicha manera acceder al uso inescrupuloso de los dineros irregularmente pactados de esa manera.

Pero, aún ante la existencia de dichas maniobras, la salida no es el señalamiento a los contratos y convenios interadministrativos como mecanismos de gestión contractual, como tampoco la lapidación de la contratación directa como modalidad de selección, sino la identificación específica de la problemática y su manifestación, para la adopción de medidas correctivas desde la Administración pública y los órganos de control, que conduzcan a extirpar esa mala práctica administrativa.

Se intentará en este trabajo responder entonces al interrogante cel convenio o contrato interadministrativo, como causal de celebración de contratos de manera directa, debe desaparecer para evitar sus malos usos? Esto, estudiando las particularidades de estas figuras, analizando la principal problemática 
que se suscita en torno a las mismas, que es la subcontratación o contratación derivada de contratos y convenios interadministrativos, y finalmente proponiendo la que consideramos una posible solución.

\section{CONTRATOS Y CONVENIOS INTERADMINISTRATIVOS. DEFINICIÓN, CARACTERIZACIÓN Y MODALIDADES SELECTIVAS}

El ordenamiento legal en Colombia aún no ha decantado la discusión en relación con la diferencia entre contratos y convenios interadministrativos ${ }^{3}$. No hay diferenciación alguna en el Estatuto General de Contratación de la Administración Pública y el ejecutivo, en virtud de potestad reglamentaria, a mi parecer excesiva pero necesaria, incluyó a los convenios como una de las causales de celebración de contratos de manera directa.

Contrario a dicha pasividad del legislador, la doctrina nacional se ha ocupado de manera profusa del tema. La posición es pacífica en torno a su delimitación conceptual y la diferenciación entre unos y otros, lo que ha sido desarrollado en el mismo sentido por parte de la jurisprudencia del Consejo de Estado.

En esta tarea de delimitación contractual debe tenerse en cuenta que tanto convenios como contratos interadministrativos son especies del contrato estatal. Ello, toda vez que si bien es cierto los primeros se utilizan como mecanismo para la persecución de intereses comunes de carácter general, es resultado de la aplicación directa del principio de autonomía de la voluntad, y cumple con las demás formalidades de los contratos.

Para este fin, inexorable resulta traer a colación y construir una definición de contrato estatal, como rango determinante de estas tipologías contractuales. No existen contratos y convenios interadministrativos en derecho privado, ni regulados en el ordenamiento jurídico civil y comercial. Así las cosas, es circunstancia básica que la legislación colombiana defina lo que para esos efectos se entiende por contrato estatal ${ }^{4}$. El artículo 32 de la Ley 80 de 1993 preconiza:

3 En ninguna norma vigente del Estatuto de Contratación se señala qué se entiende por convenio interadministrativo y cuál es la definición de contrato interadministrativo. Es más, el artículo 2 de la Ley 1150 de 2007, en el desarrollo de las causales de contratación directa, hace alusión a contratos interadministrativos. Los convenios interadministrativos se asemejan como causal de contratación directa a través de la reglamentación contenida en el Decreto 1082 de 2015.

4 La relevancia de los contratos estatales en el estudio y análisis de la doctrina permanece latente. Ello, en tanto se trata de un fenómeno jurídico caracterizado por la mixtura entre el negocio jurídico y su carácter consensuado, y además la persecución del interés general en el caso de los contratos estatales. Así lo reconocen los estudiosos, para quienes "El contrato administrativo se encuentra en la intersección de dos entramados de relaciones: como expresión del Estado cooperativo dentro de la actuación estatal consensuada, y como regulación jurídico-obligacional dentro de las actuaciones administrativas 
Artículo 32. De los contratos estatales. Son contratos estatales todos los actos jurídicos generadores de obligaciones que celebren las entidades a que se refiere el presente estatuto, previstos en el derecho privado o en disposiciones especiales, o derivados del ejercicio de la autonomía de la voluntad, así como los que, a título enunciativo, se definen a continuación ${ }^{5}$.

El legislador incurre en diferentes imprecisiones al construir la definición del contrato estatal ${ }^{6}$, pretendiendo con ello abarcar holísticamente la totalidad de la actividad contractual del Estado. La más notoria, al hacer la afirmación que son contratos estatales la totalidad de actos jurídicos generadores de obligaciones. Allí podríamos abarcar incluso los actos administrativos, las órdenes administrativas y todas aquellas actuaciones de la Administración que conlleven la transformación fenomenológica del mundo real. Todo acto de la Administración que incida en la cotidianidad de la sociedad o de un individuo determinado sería tomado como un contrato estatal.

A raíz de estas graves fallas de técnica legislativa, la doctrina y la jurisprudencia, a lo largo de la vigencia del Estatuto, han logrado entregar herramientas interpretativas para desarrollar el contrato estatal colombiano y sus reglamentaciones. En este orden de ideas, es una locución la que da sentido al precepto legal confusamente redactado: celebren. Los actos administrativos y demás tipos de decisiones de la Administración que tienen efectos jurídicos se profieren o emiten al ser voluntad unilateral de la misma. Contrario a ello, los contratos estatales se celebran. Para su nacimiento y validez se requiere la existencia de una voluntad bilateral de las partes que contraen las obligaciones recíprocas y conmutativas que constituyen el objeto contractual, y la causa de su pactación. Benavides al respecto sostiene:

jurídico-formales. Tiene, por un lado, una posición jurídica extraordinaria por su forma jurídica y por su carácter jurídico-obligacional y, por otro, se configura como modelo especial de la creación de Derecho. Resulta, por tanto, doblemente necesario disponer de una dogmática contractual idónea". Walter KREBS, "Contratos y convenios entre la administración y particulares", Revista Derecho del Estado, Universidad Externado de Colombia, 2006, p. 35.

5 Ley 80 de 1993. Disponible en línea: http://www.secretariasenado.gov.co/senado/basedoc/ ley_0080_1993.html\#32 [consultado el 28 de febrero de 2020].

6 En relación con los efectos de los contratos de la Administración, ha sostenido Jacqueline Morand-Deviller que: "Aparte de los contratos 'calificados' por el Legislador, los criterios que permiten distinguir los contratos administrativos de los contratos de derecho privado de la Administración son de origen esencialmente pretoriano. El juez fundamenta su convicción en el examen de la calidad de las personas contratantes, en la presencia o no de cláusulas exorbitantes del derecho común, en la participación o no en la ejecución de un servicio público". Jacqueline Morand-Deviller, Derecho Administrativo. Curso. Temas de Reflexión. Comentarios y análisis de fallos, Bogotá: Universidad Externado de Colombia, 2017 , p. 90 
Aunque la definición del artículo 32 es imprecisa porque incluye como acto contractual los actos ejecutorios, es decir, los actos administrativos, el Consejo de Estado ha restringido su campo a los acuerdos contractuales, lo que además puede deducirse del texto del artículo 32 cuando se refiere a los actos que celebren las entidades públicas. El acuerdo de voluntades es entonces elemento fundamental de la noción del contrato estatal, que permite diferenciarlo de otros instrumentos de creación de obligaciones como los compromisos unilaterales, corrientes en el derecho comercial (el cheque, la letra de cambio o la constitución de sociedad unipersonal), o los actos unilaterales precedidos de un acuerdo, como algunos reglamentos de intervención económica, frecuentes en el derecho administrativo francés, las obligaciones impuestas por la ley, las licencias fruto de un reglamento 7 .

Corolario de lo anterior, es posible afirmar que son tres los caracteres esenciales de los contratos estatales: a) son fruto de la autonomía de la voluntad de las partes del contrato; b) su clasificación obedece a un criterio meramente orgánico; y c) su causa es la satisfacción del interés general representado por la administración pública.

Verdad de Perogrullo es que para que los contratos estatales sean válidos, se requiere de la existencia de un consentimiento libre de vicios ${ }^{8}$. Y lo es porque desde ninguna arista, ni iusprivatista, como tampoco iuspublicista, se puede aceptar que los contratos surgen de la imposición de una de las partes en el mismo. Debe partirse necesariamente del hecho de que los contratos son parte de la fuga del derecho administrativo hacia el derecho privado, como una adaptación a las necesidades cambiantes de la sociedad. En otras palabras, el contrato estatal no es autónomo, sino que surge a partir de las construcciones del derecho civil y comercial ${ }^{9}$.

En el mismo sentido, el artículo 32 citado se refiere de manera directa a la autonomía de la voluntad privada, la que debe entenderse de forma limitada, toda vez que, acorde con lo establecido en los artículos 122 y 123 constitucional, los servidores públicos, como titulares de la potestad contractual ${ }^{10}$, solo están habilitados para ejercer aquellos actos que les son permitidos por

7 José LuIS BeNAVIDES, El contrato estatal. Entre el derecho público y el derecho privado, Bogotá: Universidad Externado de Colombia, 2010, p. 69

8 Así lo recuerda Juan CaRlos EXPÓsito VéLEZ, Forma y contenido del contrato estatal, Bogotá: Universidad Externado de Colombia, 2013, p. 117.

9 Véase artículo 13 de la Ley 80 de 1993.

10 Hago alusión de manera expresa a los determinados en el artículo 11 de la Ley 80 de 1993, norma que dispone: "Artículo 11. De la competencia para dirigir licitaciones y para celebrar contratos estatales. En las entidades estatales a que se refiere el artículo $2 .^{\circ}$ :

1. La competencia para ordenar y dirigir la celebración de licitaciones y para escoger contratistas será del jefe o representante de la entidad, según el caso.

2. Tiene competencia para celebrar contratos a nombre de la Nación, el Presidente de la República.

3. Tienen competencia para celebrar contratos a nombre de la entidad respectiva: 
el ordenamiento jurídico. En otras palabras, se pueden celebrar contratos estatales en virtud de la autonomía de la voluntad, siempre y cuando se tomen en cuenta las limitaciones propias de la función pública.

De otra parte, se afirma que su clasificación y principal característica obedece a un criterio orgánico. No ofrece discusión esta premisa. Para que se predique la existencia de un contrato y que el mismo sea calificado como estatal, deberá verificarse la existencia en uno de los extremos de la relación negocial, de una entidad estatal, tal como se define en el artículo $2 .^{\circ}$ del estatuto. Sin importar la naturaleza del contrato, el procedimiento selectivo, el uso o no de cláusulas exorbitantes, o que el mismo sea celebrado bajo un régimen exceptuado del Estatuto, será estatal todo contrato donde participe una entidad de esta naturaleza ${ }^{11}$.

En relación con la finalidad, esta dista de la clásica relación de conmutatividad, donde la causa de la obligación de una de las partes es la obtención del cumplimiento de la obligación de la otra. En la contratación estatal, tanto contratista (sujeto de derecho público o privado) como entidad contratante deben guiarse por una finalidad de orden público, en la satisfacción de intereses públicos de diferente naturaleza. La obtención de lucro o utilidad no son la razón principal ${ }^{12}$, y esta circunstancia modifica la comprensión misma de la relación contractual, sin que ello implique la inexistencia de onerosidad en este tipo de acuerdos de voluntad.

a) Los ministros del despacho, los directores de departamentos administrativos, los superintendentes, los jefes de unidades administrativas especiales, el Presidente del Senado de la República, el Presidente de la Cámara de Representantes, los Presidentes de la Sala Administrativa del Consejo Superior de la Judicatura y de sus Consejos Seccionales, el Fiscal General de la Nación, el Contralor General de la República, el Procurador General de la Nación, y el Registrador Nacional del Estado Civil.

b) A nivel territorial, los gobernadores de los departamentos, los alcaldes municipales y de los distritos capital y especiales, los contralores departamentales, distritales y municipales, y los representantes legales de las regiones, las provincias, las áreas metropolitanas, los territorios indígenas y las asociaciones de municipios, en los términos y condiciones de las normas legales que regulen la organización y el funcionamiento de dichas entidades. c) Los representantes legales de las entidades descentralizadas en todos los órdenes y niveles".

11 La jurisprudencia del Consejo de Estado en torno a esta temática ha afirmado: "Son contratos estatales todos los contratos que celebren las entidades públicas del Estado, ya sea que se regulen por el Estatuto General de Contratación Administrativa o que estén sujetos a regímenes especiales, los cuales son objeto de control por parte del juez administrativo, sin que incida la normatividad sustantiva que se le aplique a los mismos". Consejo de Estado Colombiano, Sección Tercera, auto del 22 de agosto de 2002. Expediente 1100103260002002001001 (22.193).

12 En este sentido, Benavides expresa: "El contrato estatal busca a la vez el desarrollo de misiones públicas y la obtención de beneficios. Se trata de intereses divergentes desarrollados de manera equilibrada y armoniosa por el contrato". José LuIS BENAVIDES, El contrato estatal..., óp. cit., p. 74. 
Desarrolladas estas ideas, se retoma lo que expone Santofimio Gamboa frente al concepto de contrato estatal:

Entendemos, entonces, por contrato del Estado o estatal todo negocio jurídico, de contenido económico, consecuentemente oneroso, celebrado, por regla general bajo los presupuestos del principio de igualdad, en aras del interés público o general, en el cual una de las partes es una entidad estatal, un particular que ejerce funciones administrativas en los términos de la ley, o cualquier otra persona que involucre en el mismo recursos públicos, y en razón del cual se generan, de manera discrecional, ponderada, proporcional y previsiva, obligaciones por regla general recíprocas, de dar, hacer o no hacer alguna cosa entre las partes intervinientes, construyendo, regulando o extinguiendo entre ellas relaciones jurídicas patrimoniales individuales no generales, debidamente planificadas, obligaciones que se miran como equivalentes conforme a las previsiones objetivas iniciales acordadas por las partes al momento de proponer o de contratar ${ }^{13}$.

En el mismo sentido, Expósito Vélez sostiene que el contrato estatal "es un acto jurídico lícito integrado por una o varias declaraciones de voluntad privada que el derecho reconoce como base para la producción de efectos jurídicos buscados y queridos por su autor o autores, siempre que concurran determinados requisitos o elementos ${ }^{\prime \prime}$.

Superada la tarea de definir el contrato estatal como punto de partida del contrato/convenio interadministrativo, se sigue en la labor de hallar una definición satisfactoria para estas dos instituciones, y determinar a efectos de esta disertación cuál es la diferencia entre uno y otro, máxime cuando ella será de trascendencia para la solución propuesta a la problemática indicada.

Apenas lógico es que la diferencia no sea exclusivamente semántica. Las dos alocuciones no reflejan un mismo tipo de relación jurídica. En una existe una contraposición de intereses, bajo el sentido clásico (contrato), en tanto en la otra existe una armonía plena en el cumplimiento de finalidades comunes (convenio). Esta característica es determinante para comprender ambos conceptos.

De forma específica, se puede definir como convenio interadministrativo

el negocio jurídico bilateral de la Administración en virtud del cual esta se vincula con otra persona jurídica pública o con una persona jurídica o natural privada para alcanzar fines de interés mutuo en el marco de la ejecución de funciones

13 Jaime Orlando Santofimio Gamboa, Compendio de derecho administrativo, Bogotá: Universidad Externado de Colombia, 2017, p. 624.

14 Juan CARLOS EXPÓSITO VéLEZ, La configuración del contrato de la administración pública en derecho colombiano y español. Análisis de la selección de contratistas, Bogotá: Universidad Externado de Colombia, 2003, p. 299. 
administrativas, fines que, como es obvio, siempre deberán coincidir con el interés general (artículo 209 de la Constitución Política) ${ }^{15}$.

Se denota, entonces, que la principal característica del convenio interadministrativo, rasgo diferenciador con el contrato interadministrativo, es que su finalidad única es la colaboración recíproca en ambos extremos de la relación negocial. Es más, como tal, no se está presente ante una tensión contractual propiamente dicha, sino una forma del contrato de colaboración, tal como el contrato para la conformación de un consorcio o una unión temporal ${ }^{16}$.

La comprensión de esta tipología contractual permite sintetizar que el convenio "es un negocio jurídico que, participando también del carácter formal de la condición contractual, es decir, siendo un acuerdo de voluntades generador de efectos jurídicos, vincula a las personas con el ánimo de obtener la realización de fines comunes a ambas partes" ${ }^{\prime 17}$.

De otro lado, el contrato interadministrativo

es también celebrado entre dos entidades públicas con capacidad de tener relaciones interadministrativas, con la particularidad de que el contrato es negocio jurídico generador de obligaciones al cual acuden las partes con diversidad de intereses. En el contrato se pueden identificar contratante y contratista, y el segundo, aunque persona pública, tiene intereses y está en un mercado de forma similar a como lo hace el particular ${ }^{18}$.

Jorge Enrique Santos Rodríguez, "Consideraciones sobre los contratos y convenios interadministrativos", Revista digital de Derecho Administrativo, Universidad Externado de Colombia, 2009, p. 7.

16 De esto se ha ocupado la doctrina internacional, dada la especificidad de los convenios de la administración. Concretamente en relación con los convenios entre entidades administrativas en el ordenamiento jurídico español, se sostiene: "De ahí que, desde un punto de vista abstracto, los convenios interadministrativos no puedan considerarse como un mero acto unilateral de imposición de la voluntad de una Administración pública sobre otra, ni tampoco como una sucesión de actos unilaterales propios de cada uno de los sujetos públicos que intervienen. Más bien al contrario, por cuanto, a pesar de que es cierto que la actuación de las Administraciones públicas se encuentra siempre supeditada tanto al ordenamiento jurídico como a la satisfacción de los intereses generales (artículo 103.1 CE), la libertad decisoria de las entidades públicas intervinientes jugaría un papel decisivo y regulador del contenido del convenio, proyectándose hacia una doble vertiente, esto es, para decidir libremente, en primer lugar, la formalización de dicha relación jurídica -por cuanto, para el cumplimiento de las tareas que tienen asignadas, las administraciones podrían acudir a cualquiera de los otros medios jurídicos que el ordenamiento pone a su disposición-y, en segundo lugar, la determinación de su contenido concreto". MARC VILALTA-ReIXACH, "Los convenios interadministrativos en el ordenamiento jurídico español desde un punto de vista contractual", Revista digital de Derecho Administrativo, Universidad Externado de Colombia, 2016, p. 91.

17 Augusto Ramón Chávez Marín, Los convenios de la administración. Entre la gestión pública y la actividad contractual, Bogotá: Temis, 2015, p. 51.

18 Jorge Enrique Santos Rodríguez, óp. cit. p. 11. 
Esta consideración permite colegir que siendo ambas relaciones negociales entre dos extremos que orgánicamente están clasificadas como entidades estatales y, por ende, con capacidad para celebrar contratos estatales al tenor del artículo 2. ${ }^{\circ}$ del Estatuto General de Contratación, el contrato interadministrativo implica una contraposición de intereses, en virtud de la naturaleza jurídica de la entidad estatal ejecutora o contratista, así como de la existencia de una contraprestación en el sentido más puro. Contrario sensu, el convenio interadministrativo implica la unión entre dos entidades estatales, a través del mecanismo de gestión contractual, para la obtención de un fin público de interés común, que por lo general obedece a las características de ambas entidades estatales, en tanto no obedece a una actividad comercial del Estado.

La doctrina especializada itera:

En efecto, en el "convenio", como lo establece el mencionado artículo 95 de la Ley 489 de 1998, de lo que se trata es de "cooperar en el cumplimiento de funciones administrativas o de prestar conjuntamente servicios que se hallen a su cargo". Consiste entonces de una especie de "colaboración" mutua para un propósito común, que beneficia a quienes, como administrados, deben recibir los beneficios del accionar de los entes públicos. Por contraste, en el "contrato", una de las entidades obra como verdadera "contratante", y la otra lo hace como "contratista" de manera que la primera demanda "bienes o servicios" de la segunda, quien se obliga a proveerlos en los términos del contrato. Así de simple ${ }^{19}$.

Ahora bien, conceptualizados los convenios y contratos interadministrativos, así como los rasgos que los diferencian, debe darse el paso al análisis de la modalidad de selección del contratista (aún cuando en el convenio interadministrativo ninguno de los extremos funge como tal). Se recuerda que es la Ley 1150 de 2007, complementaria de la Ley 80 de 1993, la que categoriza las modalidades de selección objetiva según cuantía y materia. Primigeniamente existían cuatro modalidades, que fueron incrementadas con la expedición de la Ley 1474 de $2011^{[20]}$.

El legislador, en su diseño del sistema de contratación estatal colombiano, quiso que la regla general en la selección objetiva de contratistas fuera la licitación pública, razón por la que son pocos los asuntos que por la materia allí se encasillan. De esta manera, serán tramitados por licitación pública todos aquellos procesos que superan la menor cuantía de la entidad estatal contratante, o aquellos que por su naturaleza no estén clasificados en ninguno de los

19 Gonzalo SuÁrez Beltrán, Estudios de derecho contractual público, Bogotá: Legis, 2014, p. 138

20 La norma del artículo 2 de la Ley 1150 de 2007 señalaba que las modalidades de selección eran: a) licitación pública ${ }_{i}$ b) selección abreviada ${ }_{i}$ c) concurso de méritos; y d) contratación directa. En el año 2011 se determinó igualmente la modalidad de la mínima cuantía, cuando el proceso de contratación no superara el 10\% de la menor cuantía de la entidad contratante. 
demás procedimientos. También la celebración de contratos de concesión y las alianzas público privadas, por manifestación expresa de la ley.

En el otro extremo, de manera excepcional, se encuentran los contratos celebrados de manera directa. Son diversas las causales establecidas en la ley, y solo ellas, puesto que se trata de circunstancias reguladas integralmente en la legislación contractual. Y lo son en razón de la materia del contrato a celebrar, sin limitación alguna en virtud del precio del contrato.

Una de las causales para la celebración de contratos a través de la modalidad de contratación directa es el contrato interadministrativo. La norma no alude al convenio interadministrativo. Empero, no se trata de una habilitación abierta. Deben cumplirse ciertos requisitos y evadirse algunas tipologías contractuales.

El artículo 2, numeral 4, literal c de la Ley 1150 de 2007 le exige al operador jurídico comprobar condiciones objetivas, pero formales, en relación con la procedencia de los contratos interadministrativos, mediante selección directa ${ }^{21}$. El primero que es obvio, es la naturaleza jurídica del ejecutor (contratista), en tanto debe ser una entidad estatal. De lo contrario, como es apenas evidente, se estaría ante un contrato cualquiera. Segundo, el objeto del contrato interadministrativo deberá tener una relación directa con el objeto de la entidad ejecutora. El profesor Solano Sierra precisa:

21 Ley 1150 de 2007, artículo 2: "De las modalidades de selección. La escogencia del contratista se efectuará con arreglo a las modalidades de selección de licitación pública, selección abreviada, concurso de méritos y contratación directa, con base en las siguientes reglas: [...] 4. Contratación directa. La modalidad de selección de contratación directa, solamente procederá en los siguientes casos: [...] c) Contratos interadministrativos, siempre que las obligaciones derivadas del mismo tengan relación directa con el objeto de la entidad ejecutora señalado en la ley o en sus reglamentos. Se exceptúan los contratos de obra, suministro, prestación de servicios de evaluación de conformidad respecto de las normas o reglamentos técnicos, encargos fiduciarios y fiducia pública cuando las instituciones de educación superior públicas o las Sociedades de Economía Mixta con participación mayoritaria del Estado, o las personas jurídicas sin ánimo de lucro conformadas por la asociación de entidades públicas, o las federaciones de entidades territoriales sean las ejecutoras. Estos contratos podrán ser ejecutados por las mismas, siempre que participen en procesos de licitación pública o contratación abreviada de acuerdo con lo dispuesto por los numerales 1 y 2 del presente artículo. En aquellos eventos en que el régimen aplicable a la contratación de la entidad ejecutora no sea el de la Ley 80 de 1993, la ejecución de dichos contratos estará en todo caso sometida a esta ley, salvo que la entidad ejecutora desarrolle su actividad en competencia con el sector privado o cuando la ejecución del contrato interadministrativo tenga relación directa con el desarrollo de su actividad. En aquellos casos en que la entidad estatal ejecutora deba subcontratar algunas de las actividades derivadas del contrato principal, no podrá ni ella ni el subcontratista, contratar o vincular a las personas naturales o jurídicas que hayan participado en la elaboración de los estudios, diseños y proyectos que tengan relación directa con el objeto del contrato principal. Estarán exceptuados de la figura del contrato interadministrativo, los contratos de seguro de las entidades estatales". 
Su viabilidad se circunscribe a que las obligaciones derivadas del vínculo contractual (objeto por ejecutar) tengan relación directa con la naturaleza funcional, legal y reglamentaria, de la entidad ejecutora [literal c, inciso $1 .^{\circ}$, ab initio]. En este sentido, no se podrá contratar, por ejemplo, la instalación de módulos de sistemas (presupuesto, nómina, recursos humanos) con una entidad del orden nacional o territorial, pues estas no tienen asignadas la realización de tales actividades [...].

El inciso $3 .^{\circ}$ autoriza la subcontratación (parcial) a las entidades ejecutoras (de alguna) de las actividades derivadas del contrato interadministrativo, con la prohibición de que no podrán ellas ni el subcontratista, contratar o vincular a las personas naturales o jurídicas que hayan participado, previamente, en la elaboración de los estudios, diseños y proyectos que tengan relación directa con el objeto del contrato principal ${ }^{22}$.

Tal como se deriva de la lectura normativa y también de la interpretación que a través de la doctrina se ha realizado de la norma habilitante, el requisito sine qua non para que sea procedente la celebración de un convenio o contrato interadministrativo se limita a la verificación de congruencia entre el objeto contractual y el objeto social de la entidad pública ejecutora. Para efectos de la discusión y previa la determinación de la problemática que se ha venido presentando, se debe comprender qué se entiende por objeto contractual. El doctrinante Expósito Vélez ilustra:

el objeto del contrato es la obligación que por él se constituye. En otros términos, podemos decir que el objeto es la consecuencia que se persigue al celebrarlo como factor determinante de la voluntad de las partes, las que al pactarlo lo pueden hacer para realizar una obra o servicio público; y, por supuesto, cualquier prestación que tenga por finalidad el fomento de los intereses y la satisfacción de las necesidades generales ${ }^{23}$.

Aclara el mismo autor que el objeto es "el efecto directo que se propone alcanzar la Administración al celebrar el contrato de que se trate ${ }^{\prime \prime 24}$. En este contexto, para que una entidad pueda seleccionar de manera directa a otra, como ejecutora de un contrato interadministrativo, basta con que estatutaria o legalmente, el objeto social le permita formalmente desarrollar las actividades a pactar como obligación del contrato ${ }^{25}$. No obstante, la laxitud de esta

22 Jairo Enrique Solano Sierra, Contratación administrativa, Bogotá: Ediciones Doctrina y Ley, 2010 , p. 335.

23 Juan Carlos Expósito Vélez, La configuración del contrato..., óp. cit., p. 287.

24 Ibíd., p. 288.

25 El tratadista Solarte Maya, coincidiendo con la posición doctrinal unificada frente a los requisitos normativos, ha señalado al respecto: "El condicionamiento que señala la Ley 1150 de 2007 en el artículo 2. ${ }^{\circ}$ numeral $4 .^{\circ}$ literal c permite la celebración de Contratos Interadministrativos siempre que las obligaciones derivadas de los mismos tengan relación 
exigencia es el origen de los usos indebidos de la tipología contractual y, por ende, de sus cuestionamientos.

\section{MANIFESTACIÓN DE LA PROBLEMÁTICA.}

\section{LA SUBCONTRATACIÓN O CONTRATACIÓN DERIVADA DE CONTRATOS Y CONVENIOS INTERADMINISTRATIVOS}

Identificado el origen del problema, esto es, la amplitud en el condicionamiento para la celebración del contrato interadministrativo a través de la modalidad de contratación directa, este, per se, no configura la discusión central de este documento. No hay lugar a la satanización del contrato o convenio interadministrativo por su existencia o por los vacíos normativos en su regulación. Este se cristaliza por la utilización irregular que de él efectúan las Administraciones públicas, con intenciones que van más allá de la materialización del interés general.

Durante el proceso de aprobación de la Ley 1150 de 2007 se discutió la confección de la norma en cuestión, argumentos de valía para el debate jurídico de fondo que se plantea. En cuanto a los debates, en el informe de ponencia para segundo debate al Proyecto de Ley 020 de 2005 del Senado de la República se determinó:

(2) El artículo 2. ${ }^{\circ}$ del pliego de modificaciones tuvo en el curso del debate los siguientes cambios:

El numeral 3 literal c relativo a la causal de contratación directa denominada contratos interadministrativos, fue objeto de una proposición modificativa, que incluía los siguientes cambios: (i) en primer orden, señalar como requisito indispensable para la celebración de un contrato interadministrativo, que las obligaciones derivadas del mismo tengan relación directa con el objeto de la entidad ejecutora. (ii) Igualmente, se prescribe que aquellas entidades ejecutoras que no estén sometidas a la Ley 80 de 1993, en todo caso deberán acatar los principios del artículo 209 de la Carta Política, el deber de selección objetiva y el régimen de incompatibilidades e inhabilidades previsto en el estatuto de contratación ${ }^{26}$.

Por su parte, es aún más contundente el Informe de Ponencia para Primer Debate de la Cámara de Representantes, en el que se iteró:

directa con el objeto de la entidad ejecutora señalado en la Ley o en sus reglamentos. [...] En aquellos casos en que la entidad estatal ejecutora deba subcontratar algunas de las actividades derivadas del contrato principal, no podrá ni ella ni el subcontratista, contratar o vincular a las personas naturales o jurídicas que hayan participado en la elaboración de los estudios, diseños y proyectos que tengan relación directa con el objeto del contrato principal". FeLIPE Alirio Solarte Maya, Contratos estatales atípicos, Bogotá: Ediciones Nueva Jurídica, 2014, p. 466.

26 Gaceta del Congreso, n. ${ }^{\circ}$ 90, 2006. Disponible en línea: http://svrpubindc.imprenta.gov.co/ senado/view/gestion/gacetaPublica.xhtml [consultado el 27 de febrero de 2020]. 
Se adoptan medidas para evitar la elusión de procesos de selección mediante las figuras de los contratos interadministrativos que hoy se han convertido en la vena rota de los recursos del Estado. En adelante se utilizará esta figura siempre que las obligaciones derivadas del mismo tengan relación directa con el objeto de la entidad ejecutora y que cuando esta deba subcontratar no quede eximida del deber de regirse por los lineamientos de la Ley 80 en cuanto a selección y demás principios que la rigen, además de imponerse la prohibición de subcontratar a las personas naturales o jurídicas que hayan participado en la elaboración de los estudios, diseños y proyectos que tengan relación directa con el objeto del contrato principal. Con ello se busca que entidades que por ejemplo se dedican a la docencia estén participando mediante figuras de contratos interadministrativos en la construcción de obras públicas, cuya ejecución entregan de manera directa a particulares y sin sometimiento a la ley de contratación estatal27.

Sin embargo, la finalidad perseguida no se obtuvo. La ausencia de técnica legislativa se ha traducido en controversias normativas, que bajo los lentes de la interpretación que se realiza por la Administración pública, convierte la reforma en ineficaz, sin que se produzcan efectos jurídicos de cara a la previsión de la violación de normas que garanticen transparencia, imparcialidad y objetividad en la selección de los contratistas. Es la norma habilitante la que abre la posibilidad de transgresión de los principios de la contratación estatal, al permitir, además, que algunas de las obligaciones contenidas en el acuerdo bilateral de dos entidades estatales sean subcontratadas. A ello se agrega que el régimen jurídico aplicable a esta contratación derivada es el Estatuto General de Contratación, siempre y cuando la entidad ejecutora no actúe en competencia con el sector privado ${ }^{28}$, o cuando el objeto del contrato o convenio interadministrativo no tenga relación con el contrato de la entidad ejecutora. Circunstancia por demás de imposible ocurrencia, en tanto solo puede celebrarse contrato interadministrativo cuando haya una relación de identidad entre el objeto contractual y el objeto de la entidad ejecutora. En caso contrario, se actuaría al margen de la ley. En otras palabras, durante la ejecución del contrato o convenio interadministrativo, se aplican las normas

27 Gaceta del Congreso, n. ${ }^{\circ} 536,2006$. Disponible en línea: http://svrpubindc.imprenta.gov.co/ senado/view/gestion/gacetaPublica.xhtml [consultado el 27 de febrero de 2020].

"El derecho a la libre competencia se convierte entonces en un límite constitucional, para la eventual procedencia de un régimen jurídico administrativo, para aquellas Administraciones públicas que desarrollen actividades económicas de naturaleza industrial y comercial en un escenario competitivo. Así mismo, desde una perspectiva material, el objeto de este tipo de actividades no pareciera encontrar una relación directa con los fines del Estado; se evidencia entonces la dificultad de percibir, en estas actividades, una manifestación de función administrativa y si así se hiciera (de manera forzada en nuestra opinión), se encontraría un límite constitucional, en absoluto insignificante, como lo es el derecho a la libre competencia". Alberto Montaña Plata, Fundamentos de derecho administrativo, Bogotá: Universidad Externado de Colombia, 2010, p. 157. 
y procedimiento de la Ley 80 de 1993, cuando el mismo devenga ilegal. Ello obedece, sin lugar a dudas, a la carencia de técnica del legislador colombiano, lo que se traduce en ineficacia y vacíos normativos.

Es inexorable recordar que un requisito de validez para los contratos interadministrativos es la coincidencia directa del objeto del acuerdo de voluntades, con el objeto social de la entidad ejecutora. La doctrina aclara que:

en este caso se autoriza seleccionar en forma directa a otra entidad estatal para que actúe como ejecutora de la actividad correspondiente y, obviamente, como debe ser, se indica que tal autorización se otorga siempre que las obligaciones derivadas del contrato interadministrativo tengan relación directa con el objeto social de la entidad ejecutora ${ }^{29}$.

La contratación derivada y la elusión de los procedimientos selectivos van unidas con los múltiples regímenes exceptuados existentes en el país, que autorizan la celebración de contratos estatales especiales. Ello, toda vez que los contratos interadministrativos mayoritariamente se celebran entre entidades territoriales y empresas sometidas a regímenes excepcionales bajo el derecho privado ${ }^{30}$.

Estos factores determinan, sin lugar a hesitación, una afectación al principio de selección objetiva, así como una demostración de una legislación altamente permisiva frente a las causales de contratación directa, que tienen una textura tan abierta, que convierten a la regla general en verdadera excepción.

Es paradójico que en el Estatuto General de Contratación de la Administración Pública, donde predominan las formas, no existan condicionamientos

30 Esta información, toda vez que entre los años 2012 y 2015, en la revisión de la información vertida en el SECOP, se celebraron 16.400 contratos y convenios interadministrativos, en los cuales se presenta, en su totalidad, contratos derivados. En ellos, en la totalidad de los casos el ejecutor es una entidad descentralizada sometida a régimen especial de contratación estatal. Matallana, analizando qué entidades podían ser ejecutoras en convenios interadministrativos, itera: "Otras entidades, sin estar sometidas al régimen de contratación del Estatuto de Contratación Estatal y teniendo su propio régimen de contratación -las normas civiles-, se consideran entidades estatales por encontrarse dentro del artículo 2 de la Ley 80 de 1993, y hay autorización legal para suscribir con ellas contratos interadministrativos: son las empresas sociales del Estado que se rigen por la Ley 100 de 1993 con las cuales los departamentos y los municipios pueden suscribir estos acuerdos para la ejecución de los recursos, por ejemplo, para atender a los vinculados o para la ejecución del Plan de Atención Básica. Igualmente se encuentran las empresas de servicios públicos domiciliarios cuando el capital es público y que al regirse por la Ley 142 de 1994, se consideran también como entidades estatales. Con ellas las entidades estatales del orden nacional, departamental o municipal pueden suscribir contratos interadministrativos para prestar los servicios que ofrecen de manera directa". ERnesto Matallana CAMACHO, Manual de contratación de la Administración pública: Reforma de la Ley 80 de 1993, Bogotá: Universidad Externado de Colombia, 2015, pp. 756-757. 
más allá de comprobaciones formales para la elusión de los procedimientos más rígidos y que garantizan una mayor pluralidad de ofertas, así como transparencia y objetividad. También lo es que, con la verificación textual de una relación directa entre el objeto social de una entidad estatal con la redacción de un objeto contractual, se autorice un contrato directo, y posteriormente se posibilite la celebración de contratos derivados, bajo regímenes de contratación sometidos a derecho privado.

La vulneración del principio de selección objetiva no deviene de la celebración de un contrato a través de la modalidad de contratación directa. Dicha interpretación no corresponde a las realidades normativas colombianas. Es, se insiste, en la causa efectiva del convenio o contrato interadministrativo en donde radica la problemática. Aun cuando en el momento de adelantar investigaciones de toda índole, por lo general, no existe prueba alguna sobre la intencionalidad en el momento de la celebración del contrato interadministrativo, la misma se puede deducir del hilo fáctico de celebración de este, e inmediatamente después la suscripción de varios acuerdos de voluntades, con regímenes especiales, baja participación de contratistas, nula publicidad, para el cumplimiento del objeto del contrato original. Se produce, formalmente, una cesión contractual, bajo formalidades, que conllevan la violación de los procedimientos selectivos.

Desde la perspectiva de la legalidad del negocio jurídico, debe adicionarse los problemas de validez de los contratos o convenios interadministrativos así celebrados, en primer lugar, por faltar a la buena fe contractual, traducida en el deber de sinceridad de las partes ${ }^{31}$, y de otra parte, en tanto siendo el contrato estatal un acuerdo de voluntades intuitu personae (en mayor razón los convenios o contratos interadministrativos, puesto que allí se presupone que la entidad estatal ejecutora es quien tiene la experticia en el desarrollo del objeto pactado), la existencia de un error sobre las calidades de la persona conlleva un vicio del mismo.

No se trata de una circunstancia de menor envergadura. Se olvida, por parte de los competentes contractuales en el momento de suscribir convenios o contratos interadministrativos, que estos se celebran por las calidades del ejecutor. No se trata solo de una coincidencia textual entre el objeto

31 Unas de las principales obligaciones derivadas de la buena fe que caracteriza a las partes de un negocio jurídico son la claridad y la sinceridad. Estas se refieren a dar a conocer al otro sujeto del negocio jurídico sobre las condiciones específicas de cumplimiento de las obligaciones derivadas del acuerdo de voluntades. Por ello, Hinestrosa llama la atención en este aspecto: "Quienquiera que entre o permanezca en una negociación tiene delanteramente un deber de sinceridad: decir la verdad y toda la verdad (artículos 14 y 15 del Decreto 3466 de 1982), ser transparente, que va de suyo, pero que bien puede ser reforzado con un pacto o cláusula a propósito". FernANDo HinEsTrosa. Tratado de obligaciones, t. II, De las fuentes de las obligaciones: el negocio jurídico, Bogotá: Universidad Externado de Colombia, 2015, p. 393. 
contractual, sino que además ello debe conllevar una ventaja comparativa automática, que justifique la escogencia directa del contratista. Esto implica que, al seleccionar a un ejecutor contractual de naturaleza pública, de forma directa, por sus calidades, pero este, a su vez realiza una contratación derivada, donde traslada la responsabilidad y ejecución del objeto del convenio en su totalidad, se configura un error en el consentimiento, que pone en riesgo la legalidad del bilateral.

En relación con estos aspectos, se ha aseverado:

En los más de los negocios no importa la persona con quien se celebra o que recibe sus efectos, interesan solamente las consecuencias del trato; la persona es fungible, intercambiable. Sin embargo, casos se dan en los que la prestación es personalísima o personalmente calificada, o la atribución patrimonial se otorga a favor de un sujeto determinado por sí mismo o por sus relaciones o antecedentes con quien dispone; allí, porque el ordenamiento lo permite, sí puede tener influencia el error sobre la identidad de la persona o sobre las calidades de esta, mas no sobre su simple nombre (artículo 1116 CC). Esta personalización puede ser unilateral, o bilateral que es lo más frecuente. Lo fundamental es que la identidad o las calidades de la persona hayan sido conditio sine qua non del consentimiento o de la contratación, en el caso concreto ${ }^{32}$.

La obligatoriedad de hacer énfasis en el asunto surge cuando se reconoce que

Con todo, es razonable pensar que es importante, y puede adquirir caracteres definitivos, no solamente la identidad de la otra parte o del destinatario de la asignación, sino también, y en ocasiones con mayor énfasis, sus calidades. Las calidades esenciales de la persona, las calidades esenciales de la prestación, estas con dependencia íntima de aquellas ${ }^{33}$.

Tal como se anotó, la Procuraduría General de la Nación, a través de sus diferentes despachos, ha adelantado investigaciones e impuesto sanciones a servidores públicos por la indebida utilización de contratos interadministrativos. El cuestionamiento común es la inexistencia de capacidad operativa para el cumplimiento de las obligaciones del contrato interadministrativo, es decir, que la contrastación del objeto de la entidad ejecutora no es suficiente para salvaguardar los principios de transparencia y selección objetiva, sino que debe existir realmente la posibilidad de ejecución de las obligaciones contenidas en el bilateral.

En proceso que se adelantó por la celebración de un convenio interadministrativo en la ciudad de Manizales, precisó dicho ente de control: 
Es necesario igualmente recalcar, a tono con el a quo, que la ejecución propiamente dicha de la relación contractual que nos ocupa, no es objeto de cuestionamiento en esta actuación disciplinaria, por ello la efectividad que alegaron los disciplinados en nada mengua la imputación realizada. Lo propio sucede con el trámite surtido para seleccionar el aliado estratégico por parte de InfoManizales y aunque en la parte final de la imputación al señor alcalde de Manizales el a quo hizo mención a la selección directa de este Aliado, en nada mengua la imputación central, que se repite, consistió en la violación del principio de transparencia de la contratación estatal, al desconocerse el proceso reglado de selección objetiva del contratista, tratándose de la celebración del llamado convenio interadministrativo, pues en lugar de haberse agotado el proceso de licitación pública, se acudió a la contratación directa, desnaturalizando la concepción de un verdadero convenio interadministrativo. En la presente actuación se estableció la incapacidad de InfoManizales, tanto que fue y es su aliado estratégico quien ejecuta la mayoría de las obligaciones que se pactaron en el contrato de concesión y así se concibió en los mismos estudios previos realizados, tal y como se decantó en esta providencia. Por ello es que técnicamente hablando no podríamos ubicar la ejecución que realiza el tercero (Consorcio Servicio de Tránsito de Manizales) en una subcontratación propiamente dicha, a pesar de que la realidad nos muestra que es este ente el que desarrolla el objeto de la concesión, pero, aun así, trátese de subcontratación o no, lo cierto es que se desdibujó el convenio interadministrativo. Es preciso recalcar que en la imputación fáctica y jurídica en nada incide la forma en que se seleccionó por parte de InfoManizales a este aliado estratégico, pese a que en el cargo imputado se hizo mención a esta situación, error de técnica que no tiene la virtualidad de desvirtuar el reproche, que cobró sustento luego de finiquitada la actuación disciplinaria ${ }^{34}$.

En proceso posterior se mantiene dicha posición, cuando la Sala Disciplinaria de la Procuraduría General de la Nación, cuestionando la celebración de múltiples contratos interadministrativos que a su vez desembocaron en contratación derivada, afirmó:

es preciso reiterar que no se evidencia que los convenios interadministrativos cuestionados tuvieran como finalidad la unión de esfuerzos, o la cooperación entre las entidades intervinientes, y mucho menos que el propósito de su celebración fuera el de obtener un rendimiento y optimización de los dineros públicos como indicó el recurrente, en cambio, la realidad procesal demostró que a través de ellos se evadieron los procesos de selección y se terminó convirtiendo en una tercerización de la contratación, porque las empresas estatales contratadas para ejecutar las obras y elaborar los diseños y estudios terminaron subcontratando la

34 Procuraduría General de la Nación, Sala Disciplinaria, fallo de segunda instancia del 6 de noviembre de 2014, radicación 161-5322. 
totalidad de las obligaciones pactadas, porque carecían de la capacidad técnica, operativa y de infraestructura para ejecutarlos directamente ${ }^{35}$.

Es una realidad que la carencia de capacidad operativa por parte de la entidad ejecutora, conduce, sin dubitación, a la celebración posterior de contratos derivados que, al realizar una revisión completa, permitiría colegir una cesión completa de las obligaciones, o de su gran mayoría. Es allí donde reside la evidencia de una ausencia de capacidad y una falsa causa en la celebración del contrato o convenio interadministrativo.

Esto, por demás, tiene asidero en que en la elaboración de los estudios previos y en la proyección del acto administrativo que justifica la celebración del contrato a través de la modalidad de contratación directa, la entidad estatal contratante señala las razones por las cuales es benéfico y conveniente acudir a dicha tipología contractual, las cuales no pueden ser otras que la satisfacción de la necesidad pública ${ }^{36}$. Sin embargo, la entidad ejecutora no está en capacidad de satisfacer la necesidad de manera directa, con lo cual quedan los rastros suficientes para aludir a un quebrantamiento normativo.

Estas maniobras se agudizan ante la existencia de regímenes exceptuados en muchos casos no justificados, que facilitan rodear las modalidades de selección más transparentes, públicas y con mayor libertad de concurrencia, para el direccionamiento de la celebración de contratos, bajo égidas de corrupción administrativa. Asimismo, ponen en evidencia la necesidad de adoptar medidas correctivas (no sancionatorias, pero tampoco las excluyen), para salvaguardar los fines públicos involucrados en la celebración de contratos estatales ${ }^{37}$.

Como se deduce de lo expuesto, no es el contrato o convenio interadministrativo, de manera aislada, el problema. La sintomatología se encuentra en la recurrencia a contratos derivados, sin la aplicación de las formalidades de los procedimientos selectivos más complejos, y la aplicación de normas de derecho privado aplicables a las entidades estatales con regímenes contractuales

35 Procuraduría General de la Nación, Sala Disciplinaria, fallo de segunda instancia del 27 de abril de 2018, radicación 161-7187.

36 Relevante resulta enfatizar en la naturaleza jurídica de las entidades ejecutoras, la cual, por estar en competencia con el sector privado, se ciñe a las lógicas económicas de la oferta y la demanda. Esto afecta de manera simultánea la contratación derivada, que siendo irregular, busca finalidades diferentes a las que persigue la entidad contratante original. Ello, toda vez que "En estas condiciones, la decisión sobre la contratación y sobre la escogencia del contratista de una empresa privada está orientada por las reglas del mercado y la lógica de la competencia. Por el contrario, la decisión contractual de una entidad pública está orientada por la rentabilidad pública de las políticas públicas que buscan la pulcritud del gasto público, así como el incentivo de ciertas actividades y sectores importantes para el desarrollo general de la economía de un país". JosÉ LuIs BENAVIDES, Contratos públicos. Estudios, Bogotá: Universidad Externado de Colombia, 2014, p. 115. 
especiales. Por consiguiente, es en relación con esto último con lo que deben construirse soluciones no solo administrativas, sino también sociales y legislativas.

\section{A MANERA DE CONCLUSIÓN: UNA POSIBLE SOLUCIÓN}

Determinada la especificidad del problema público contractual que se presenta, así como de la existencia recurrente de violaciones al ordenamiento jurídico y a los principios de la contratación estatal, queda un pequeño resquicio diferente a la erradicación de los convenios o contratos interadministrativos como medios de gestión de la Administración.

Sea lo primero señalar que el cambio urgente e inmediato, más que legislativo, es cultural y comunicacional. Los instrumentos contractuales administrativos a los que aludimos no son por sí mismos perjudiciales o violatorios de normas de obligatorio cumplimiento. Son los operadores jurídicos quienes tergiversan su uso para el aprovechamiento individual de los recursos que pertenecen a la comunidad. De esta manera, el convenio o contrato interadministrativo no solo debe circunscribirse a la verificación de requisitos eminentemente formalistas (coincidencia de objetos), sino a la satisfacción de intereses generales. No pueden ser solo la traducción de una causal de evasión de la licitación pública o cualquier otro mecanismo de selección objetiva de contratistas, sino que deben responder al cumplimiento de objetivos comunes y armónicos de las entidades estatales convocadas.

Es aquí donde la noción de objeto debe comprenderse, no desde la transliteración de un objetivo societario, en un objeto contractual. Por el contrario, orgánica y funcionalmente deberá comprender las tareas diarias que directamente ejecuta la entidad contratista o directamente obligada a través de la celebración del contrato interadministrativo. Es decir, no será suficiente que la entidad tenga en sus estatutos la posibilidad de construcción de obra civil, sino que, además, deberá verificarse que estructural, presupuestal y orgánicamente ejecuta obras civiles de manera directa. Ello evitará la celebración mayoritaria de contratos derivados para dar cumplimiento al contrato o convenio interadministrativo. Si bien obedece a modificaciones comunicacionales y de ideología del servidor público, tiene el poder suficiente para materializar transformaciones sustanciales para el problema jurídico que se presenta. El maestro García de Enterría, frente a situaciones similares, señalaba: "Que no se diga que la palabra sea poca cosa en esos momentos. Palabra y acto es la misma cosa. La afirmación poderosa y enérgica que tranquiliza los corazones es una creación de actos; lo que la palabra dice, a la vez lo produce ${ }^{\prime \prime 38}$. 
La modificación de la estrategia comunicacional, liderada a través de la imposición de sanciones ejemplarizantes en derecho disciplinario, así como las actuaciones preventivas de los diferentes órganos de control, permitirán, de primera mano, una solución transitoria a la cuestión planteada.

Asimismo, y con el fin de instituir soluciones más profundas, deberán implementarse cambios legislativos. Estos por demás no sobre la base de intereses individuales o colectivos de los congresistas que protejan de manera irregular fuentes de ingresos ilegales. Por el contrario, deberán responder a la exigencia social de erradicación de prácticas corruptas, así como de la inversión pública real. Se deberán emitir normas legítimas, racionales, que limiten la aplicación del contrato o convenio interadministrativo a situaciones de cumplimiento de fines públicos. Habermas, frente a la legitimidad como componente importante de la vida normativa, iteró:

la legitimidad de las reglas se mide por la desempeñabilidad o resolubilidad discursiva de su pretensión de validez normativa, y en última instancia atendiendo a si han sido producidas en un procedimiento legislativo que quepa considerar racional, o a si por lo menos hubieran podido ser justificadas desde puntos de vista pragmáticos, éticos y morales. La legitimidad de una regla es independiente de su imposición o implementación fáctica ${ }^{39}$.

No se trata de medidas populistas que respondan a los llamados de los medios de comunicación. Tampoco de la limitación a titulares de prensa que son los grandes motivadores de las reformas legislativas en el país. Serán, sin dudarlo, modificaciones específicas en torno a detalles de la ejecución de los contratos o convenios interadministrativos, las que revelen la limitación de la arbitrariedad de la administración pública en asuntos contractuales.

Una reforma imprescindible es eliminar la posibilidad de subcontratación por medio de regímenes exceptuados. Esta es la ruta de escape que se utiliza para la triangulación de los recursos del erario. Es decir, al celebrarse un contrato o convenio interadministrativo, bajo ninguna circunstancia el ejecutor del mismo podrá acudir a regímenes diferentes del Estatuto General de Contratación de la Administración Pública. La razón: al mantener la pureza de los procedimientos selectivos se obliga al operador jurídico a recurrir al contrato o convenio interadministrativo solo cuando sea realmente procedente. Se reducen los márgenes de discrecionalidad o arbitrariedad, excluyendo la posibilidad de falsas causas como las que se presentan comúnmente en este ámbito.

En la misma línea, la subcontratación o contratación derivada solo será posible bajo parámetros de razonabilidad, necesidad e idoneidad, sin que se traslade la obligación principal del contrato o convenio interadministrativo a 
un particular. Para ello pueden imponerse límites cuantitativos y cualitativos para la entidad ejecutora. Es decir, imponer restricciones de subcontratación a un margen porcentual mínimo. Es posible deducir que ambas reformas reducirían a su expresión mínima el uso de los convenios y contratos interadministrativos. También lo mantendrían como instrumento de gestión, mas no como excusa al cumplimiento de las obligaciones de los servidores públicos. Todo, en el marco conceptual de un Estado social de derecho como el colombiano, pudiéndose colegir que "El Estado de derecho es enemigo de los excesos, es decir, del uso 'no regulado' del poder. La generalidad de la ley comporta una 'normatividad media', esto es, hecha para todos, lo que naturalmente contiene una garantía contra un uso desbocado del propio poder legislativo" ${ }^{\prime 40}$. Es posible preguntarse, tal como al inicio de esta disertación, cel convenio o contrato interadministrativo como causal de celebración de contratos de manera directa debe desaparecer para evitar sus malos usos? La respuesta es negativa. Se ha logrado demostrar que dicho instrumento contractual no es negativo. Es la interpretación del operador jurídico la que conduce a su cuestionamiento recurrente ${ }^{41}$.

\section{BIBLIOGRAFÍA}

\section{DOCTRINA}

BenAVIDES, José Luis. El contrato estatal. Entre el derecho público y el derecho privado. Bogotá: Universidad Externado de Colombia, 2010.

Benavides, José Luis. Contratos públicos. Estudios. Bogotá: Universidad Externado de Colombia, 2014

Chávez Marín, Augusto Ramón. Los convenios de la administración. Entre la gestión pública y la actividad contractual. Bogotá: Temis, 2015.

Expósito Vélez, Juan Carlos. Forma y contenido del contrato estatal. Bogotá: Universidad Externado de Colombia, 2013.

40 Gustavo Zagrebelsky, El derecho dúctil, 11. a ed., Madrid: Editorial Trotta, 2016, p. 29

41 Tal como se pregunta el tratadista Suárez Beltrán, csignifica la exigencia de que el objeto del contrato pueda ser ejecutado por la entidad "contratista" que ella no pueda celebrar "subcontratos"? No, ciertamente no, toda vez que la "subcontratación" no solo no está prohibida en el Estatuto General de Contratación, sino que el propio literal c mencionado en su penúltimo inciso alude a tal posibilidad en relación con "algunas de las actividades". En todo caso, ello no podrá usarse para burlar las formas de selección, aspecto en relación con el cual el operador jurídico deberá emplear su mejor criterio para evitarlo. GonZALO SuÁreZ Beltrán, óp. cit., p. 141. 
EXPÓSITO Vélez, JuAn Carlos. La configuración del contrato de la administración pública en derecho colombiano y español. Análisis de la selección de contratistas. Bogotá: Universidad Externado de Colombia, 2003.

García de Enterría, Eduardo. La lengua de los derechos. La formación del derecho público europeo tras la Revolución francesa. Madrid: Real Academia de la Lengua Española, 1994.

Habermas, Jurgen. Facticidad y validez, 6. ${ }^{a}$ ed. Madrid: Editorial Trotta, 2010.

Hinestrosa, Fernando. Tratado de obligaciones, t. II, De las fuentes de las obligaciones: el negocio jurídico. Bogotá: Universidad Externado de Colombia, 2015.

KREBS, WALTER. "Contratos y convenios entre la administración y particulares". Revista Derecho del Estado, Universidad Externado de Colombia, 2006.

Matallana Camacho, ERnesto. Manual de contratación de la Administración pública: Reforma de la Ley 80 de 1993. Bogotá: Universidad Externado de Colombia, 2015.

Montaña Plata, Alberto. Fundamentos de derecho administrativo. Bogotá: Universidad Externado de Colombia, 2010.

Morand-Deviller, Jacqueline. Derecho Administrativo. Curso. Temas de Reflexión. Comentarios y análisis de fallos. Bogotá: Universidad Externado de Colombia, 2017.

Santofimio Gamboa, Jaime Orlando. Compendio de derecho administrativo. Bogotá: Universidad Externado de Colombia, 2017.

Santos Rodríguez, Jorge Enrique. "Consideraciones sobre los contratos y convenios interadministrativos". Revista digital de Derecho Administrativo, Universidad Externado de Colombia, 2009.

Solano Sierra, Jairo Enrique. Contratación administrativa. Bogotá: Ediciones Doctrina y Ley, 2010.

Solarte Maya, Felipe Alirio. Contratos estatales atípicos. Bogotá: Ediciones Nueva Jurídica, 2014.

Suárez Beltrán, Gonzalo. Estudios de derecho contractual público. Bogotá: Legis, 2014.

Vilalta-Reixach, Marc. "Los convenios interadministrativos en el ordenamiento jurídico español desde un punto de vista contractual". Revista digital de Derecho Administrativo, Universidad Externado de Colombia, 2016.

Zagrebelsky, Gustavo. El derecho dúctil, 11. ${ }^{a}$ ed. Madrid: Editorial Trotta, 2016. 
Jurisprudencia del Consejo de Estado

Sala de Consulta y Servicio Civil, concepto de 10 de mayo de 2016. Radicación 2271.

Sala de Consulta y Servicio Civil, concepto del 28 de junio de 2012. Radicación 2092.

Sección Cuarta, sentencia del 22 de septiembre de 2016. Radicación 20561.

Sección Tercera Subsección A, sentencia del 10 de agosto de 2016. Radicación 34369A.

Sección Tercera, auto del 22 de agosto de 2002. Expediente 1100103260002002001001 (22.193).

Sección Tercera, sentencia del 22 de octubre de 2012. Radicación 22760.

Sección Tercera, sentencia del 24 de marzo de 2011. Radicación 18118.

Sección Tercera, sentencia del 28 de mayo de 2015. Radicación 29661.

Sección Tercera, sentencia del 31 de enero de 2011. Radicación 17767.

Sección Tercera, sentencia del 8 de febrero de 2012. Radicación 20688

Sección Tercera, Subsección C, sentencia del 31 de agosto de 2015. Radicación 37463.

Sección Tercera, Subsección C, sentencia del 6 de mayo de 2015. Radicación 30917.

Fallos de la Procuraduría General de la Nación

Sala Disciplinaria, fallo de segunda instancia del 27 de abril de 2018. Radicación 161-7187.

Sala Disciplinaria, fallo de segunda instancia del 3 de abril de 2014. Radicación 161-5532.

Sala Disciplinaria, fallo de segunda instancia del 6 de noviembre de 2014. Radicación 161-5322.

Viceprocuraduría General de la Nación, fallo del 27 de mayo de 2009. Radicación 154-164891-07. 